\title{
Nocardiosis: Updated Clinical Review and Experience at a Tertiary Center
}

\author{
J. Ambrosioni, D. Lew, J. Garbino
}

\begin{abstract}
Nocardiosis is a rare opportunistic disease that affects mainly patients with deficient cell-mediated immunity, such as those with acquired immunodeficiency syndrome (AIDS) or transplant recipients. Pulmonary disease is the most common presentation in immunosuppressed patients and approximately one-third have a disseminated disease. Primary cutaneous nocardiosis is more frequently observed in immunocompetent patients with direct inoculation of the organism through professional exposure. The diagnosis can be challenging, as signs and symptoms are not specific and a high index of clinical of suspicion is necessary. Although gram stain, modified acid-fast stain, and cultures remain as the standard diagnostic tools, novel molecular techniques have changed the taxonomy of these organisms and, in some instances, have facilitated their identification. The disease has a marked tendency to recur and a high morbidity and mortality rate in immunosuppressed patients. Treatment is usually prolonged and an associated antibiotic treatment is preferred for severe disease. Although sulfonamides in combination with other antibiotics are still the treatment of choice, other associations such as imipenem plus amikacin are preferred in some centers. Linezolid is a useful alternative therapeutic agent due to its oral availability and activity against most of the isolates studied. Twenty-eight cases of nocardiosis were diagnosed at our center between January 1989 and April 2009. We report the epidemiologic characteristics of Nocardia spp. observed in our institution and discuss the risk factors, clinical features, diagnosis, and management of the disease.
\end{abstract}

Infection 2010; 38: 89-97

DOI 10.1007/s15010-009-9193-9

\section{Introduction}

Nocardiosis is a localized or disseminated infection caused by the actinomycete Nocardia spp. that affects mainly immunocompromised patients [1]. It has been reported more frequently in patients with varying types of deficient cell-mediated immunity, such as those with acquired immunodeficiency syndrome (AIDS) or organ transplant recipients, with an incidence in these groups 140-340-fold higher than in the general population [2]. Clinical presentation can be acute, sub-acute, or, more frequently, chronic. Nocardiosis has a high morbidity and mortality rate, which has been reported to be between 7 and $44 \%$ for disseminated nocardiosis. The disease also has a marked tendency to recur. Immunocompetent patients usually develop localized cutaneous lesions, such as cellulitis, abscesses, or sporotrichoid forms [1].

\section{Epidemiology, Pathogenesis, and Risk Factors}

Nocardia spp. are ubiquitous soil organisms with more than 50 species that have been isolated from clinical infections [1,3]. Nocardiosis has been reported worldwide in all ages and ethnic groups. It is two to three times more common in men, but there is no clear explanation for this gender predominance [4-7]. Nocardia is not part of the normal human flora and any isolate must be carefully evaluated [4].

The organisms are readily aerosolized with dust, especially in dry areas. Consequently, the respiratory tract is the main portal of entry, with 50 to $70 \%$ of cases presenting with pulmonary involvement, most commonly with organisms representing the former $N$. asteroides complex [8]. Bronchiectasis and other structural lung abnormalities have been reported as an important risk factor for respiratory colonization by Nocardia spp. [9].

Organisms can also be acquired by direct inoculation, resulting in primary infections of the skin and subcutaneous tissues, often presenting as a localized, nodular process. These infections can progress via lymphatic spread to regional nodes and, occasionally, by direct spread to contiguous joints and bones [3]. Agricultural work represents an important risk factor, with $N$. brasiliensis being the most common infecting species. Chronic

\footnotetext{
J. Ambrosioni, D. Lew, J. Garbino (corresponding author) Division of Infectious Diseases, Faculty of Medicine, University Hospitals of Geneva, 4 Rue Gabrielle Perret-Gentil, 1211 Geneva 14, Switzerland; Phone: (+41/22) 372-9839, Fax: -9832, e-mail: jorge.garbino@hcuge.ch
}

Received: June 3, 2009 - Revision accepted: December 7, 2009 Published online: March 20, 2010 
cutaneous infections evolving over months to years may result in a mycetoma (actinomycetoma) [3, 10-12].

The pace and course of infection is closely related to the immune competence of the host. Infections in immunocompetent hosts are typically chronic processes, localized to a single organ or region. In contrast, hematogenous dissemination, frequently involving the central nervous system and skin, is characteristic of immunocompromised hosts. Nocardiosis has been observed in a wide range of conditions associated with impaired cell-mediated immunity [13-17], including solid organ and hematopoietic stem cell transplantation, AIDS, hematologic and solid organ malignancies, and chronic systemic steroid use. Patients presenting with disseminated nocardiosis should be carefully evaluated for defects in host immunity.

Twenty-eight cases of nocardiosis were diagnosed at the University Hospitals of Geneva between January 1989 and February 2009 (Table 1). These cases represent an update of our experience since the previous report by Matulionyte et al. [5]. Similar to other centers, we observe nocardiosis to be an emerging disease, since four cases were diagnosed during 2008, and three during the first four months of 2009. This could be related to the increased number of immunocompromised patients at our center. Although earlier reports from the United States estimated the incidence of nocardiosis at $500-1,000$ cases per year [6], it is now increasingly observed, probably due to the rise in the number of immunosuppressed patients over the last several decades.

At our center, 23 ( $82 \%$ ) of 28 patients had at least one predisposing condition associated with immunocompromise (Table 1). Three other patients with chronic, structural, pulmonary disease (cystic fibrosis, chronic obstructive pulmonary disease [COPD], and bronchiectasis) were considered to be chronically colonized, but did not develop invasive infection. In addition, three patients had primary cutaneous nocardiosis and one developed a septic arthritis after trauma (Table 1).

The frequency of nocardiosis in solid organ transplant recipients varies between 0.7 and $3 \%$, and has mostly been reported in heart, kidney, liver, and lung transplant recipients [18]. At our institution, 25\% (7) of the patients were solid organ transplant recipients. The incidence of nocardiosis is approximately 340 -fold higher among bone marrow transplant recipients than in the general popula-

Table 1

Nocardiosis characteristics of 28 patients with invasive infection at the University Hospitals of Geneva, $\boldsymbol{n}$ (\%).

\begin{tabular}{|c|c|c|c|}
\hline Characteristic & Cutaneous $(n=4)^{a}$ & Pulmonary $(n=20)^{b}$ & CNS and disseminated $(n=4)^{c}$ \\
\hline \multicolumn{4}{|l|}{ Underlying condition } \\
\hline Solid organ transplantation ${ }^{\mathrm{d}}$ & & $6(30)$ & 1 (25, disseminated form) \\
\hline Solid organ malignancy & $1(25)$ & $3(15)$ & $1(25)$ \\
\hline Diabetes mellitus & & $3(15)$ & $1(25)$ \\
\hline HIV infection & & $3(15)$ & \\
\hline Other immunodeficient condition ${ }^{f}$ & & $3(15)$ & $1(25)$ \\
\hline Corticosteroids 1 month previous to nocardiosis & & $8(40)$ & $2(50)$ \\
\hline Coinfections $^{g}$ & & $6(30)$ & \\
\hline \multicolumn{4}{|l|}{ Nocardia spp. } \\
\hline N. asteroides & & $12(60)$ & $1(25$, disseminated form $)$ \\
\hline N. asteroides complex & & $2(10)$ & $2(50)$ \\
\hline N. farcinica & & $2(10)$ & \\
\hline N. nova & & $1(5)$ & \\
\hline N. brasiliensis & $1(25)$ & & \\
\hline Not identified & $3(75)$ & $3(15)$ & $1(25)$ \\
\hline \multicolumn{4}{|l|}{ Outcome } \\
\hline Cure/improvement & $4(100)$ & $15(75)$ & $3(75)$ \\
\hline Failure $^{\mathrm{h}}$ & & $1(5)$ & \\
\hline Relapse $^{i}$ & & $1(5)$ & \\
\hline Death & & $3(15)$ & 1 (25, disseminated form) \\
\hline
\end{tabular}

Including three cases of primary cutaneous nocardiosis and one case of arthritis

${ }^{\mathrm{b}}$ Nocardia recovered only from respiratory samples (disseminated cases not included)

'Including three cases of isolated CNS involvement and one disseminated case (Nocardia recovered form blood, lung, and peritoneum)

denal in three patients, cardiac in two patients, pulmonary in one patient, and hepatic in one patient

eBreast in three patients, prostate and tongue in one patient each

${ }^{\mathrm{f}}$ Idiopathic lymphopenia, chronic granulomatous disease, common variable immunodeficiency, multiple myeloma

${ }^{g}$ Pneumocystis jirovecii pneumonia in an HIV patient, tuberculosis in a patient with cancer, CMV infection in a cardiac and in a renal transplant recipient, Mycobacterium intracellulare, CMV, and Toxoplasma spp. infection in a cardiac transplant recipient, pulmonary aspergillosis in a liver transplant recipient

${ }^{\mathrm{h}}$ Defined as no initial response to treatment

iDefined as initial response followed by clinical worsening on treatment 
tion [2]. Although nocardiosis is rare within the first month after organ transplantation, it must be considered if aggressive immunosuppression has been used. High-dose steroid therapy, a history of cytomegalovirus disease, and high levels of calcineurin inhibitors have been described as independent risk factors for Nocardia infection among organ transplant recipients [19].

Among patients with AIDS, the incidence of nocardiosis is approximately 140 -fold higher than in the general population [2]; patients with a low CD4 T-cell count (less than 100 cells $/ \mathrm{mm}^{3}$ ) are at the highest risk [20]. In HIV-positive patients, the clinical picture of pulmonary nocardiosis, with or without dissemination, may be very similar to tuberculosis [21], thereby, leading to delay in diagnosis and, subsequently, poor outcome [22]. Although the overall incidence of nocardiosis among AIDS patients is low (between 0.1 and $0.4 \%$ ), it is associated with high morbidity and mortality rates $[23,24]$. At our center, $11 \%$ (3) patients were HIV-positive (Table 1). Conventional trimethoprim-sulfamethoxazole prophylaxis may reduce the rate of nocardial infection in transplant recipients and AIDS patients; however, cases have been reported in patients receiving such treatment $[25,26]$.

Prolonged therapy with systemic corticosteroids causes a selective suppression of the Th1-cellular immunity [27] and has been reported as a major predisposing factor for pulmonary and disseminated nocardiosis. Steroids are also frequently associated with other predisposing conditions, such as chronic pulmonary disease or transplantation. At our institution, 36\% (10) of the patients were on steroid therapy at the time of nocardiosis (Table 1).

Solid organ tumors and oncohematologic malignancies, with or without concurrent chemotherapy or corticosteroids, have been reported as important predisposing factors for nocardiosis [5, 28-32]. At our center, 18\% (5) of the patients had solid organ malignancies and one had an oncohematologic malignancy (Table 1).

There is no definitive evidence of person-to-person transmission of Nocardia infection and respiratory or contact isolation are not recommended [23].

\section{Clinical features}

No internationally accepted disease classification is available for nocardiosis. However, commonly accepted, standard, clinical categories are pulmonary, disseminated, and primary cutaneous nocardiosis.

Cutaneous nocardiosis is caused mostly by $N$. brasiliensis $[23,25]$.

Immunocompetent patients with traumatic inoculation at the infected site may develop superficial cutaneous disease (primary cutaneous nocardiosis), lymphocutaneous disease (sporotrichoid nocardiosis), or actinomycetomas. Lymphocutaneous disease must be differentiated from sporotrichosis and other subcutaneous mycosis, as the clinical presentation can be very similar, with affectation of both lymphangitic vessels and lymph nodes.
Actinomycetomas caused by Nocardia spp. must be differentiated from those produced by other actinomycetes and by those produced by fungus, and although the evolution of those caused by Nocardia is normally faster, they cannot be differentiated clinically [33].

Pulmonary nocardiosis is caused by numerous species and is more frequently encountered in patients with structural pulmonary disease, as they are more susceptible to colonization. The clinical presentation can be acute, sub-acute, or chronic pneumonia, and the multiple radiographic presentations include lobar infiltrates, abscesses, cavities, pleural effusion, or pulmonary nodules (Figure 1). Although there is no specific pattern, cavities are frequently found, particularly among HIVinfected individuals [20]. Patients chronically infected may present weight loss and a persistent cough over many weeks, and tuberculosis must always be excluded. Lung abscesses produced by other bacteria and lung cancer are other important differential diagnoses and are very difficult to distinguish clinically. Although less frequent, immunocompetent patients can also present with pulmonary nocardiosis. In our case series, $71 \%$ (22) of the patients presented with pulmonary infection, with fever and cough $(60 \%$ each $)$ as the most frequent symptoms.

Disseminated nocardiosis may be caused by numerous species. In most cases, dissemination is from the lungs and involves more frequently the central nervous system, skin, and the soft tissues. This is typically observed in severely immunocompromised patients (transplant recipients, AIDS). Nocardia spp. are responsible for the initial cutaneous or neurological clinical symptoms in some cases, and the pulmonary affectation is evidenced only thereafter. The involvement of the central nervous system should always be excluded in immunosuppressed patients, even without neurological symptoms. Cerebral abscesses

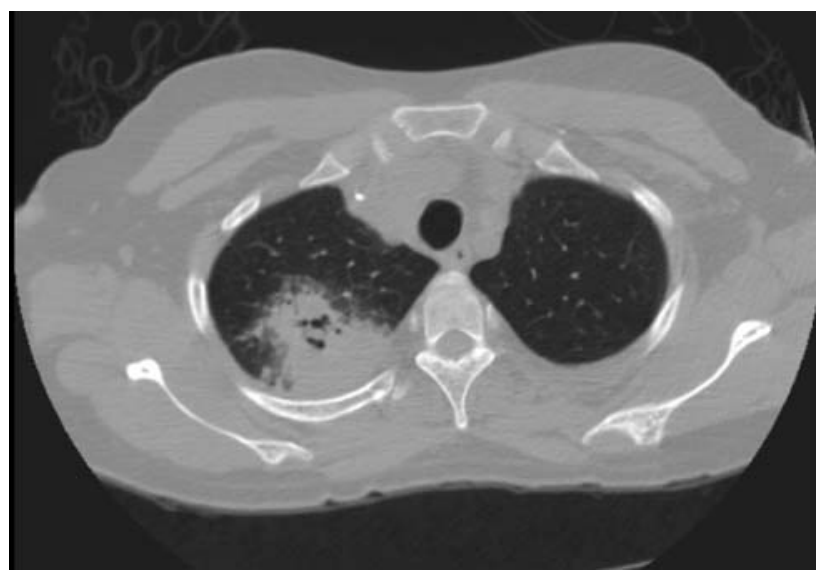

Figure 1. Chest computed tomography (CT) scan. Pneumonia due to Nocardia spp. in a renal transplant recipient. 


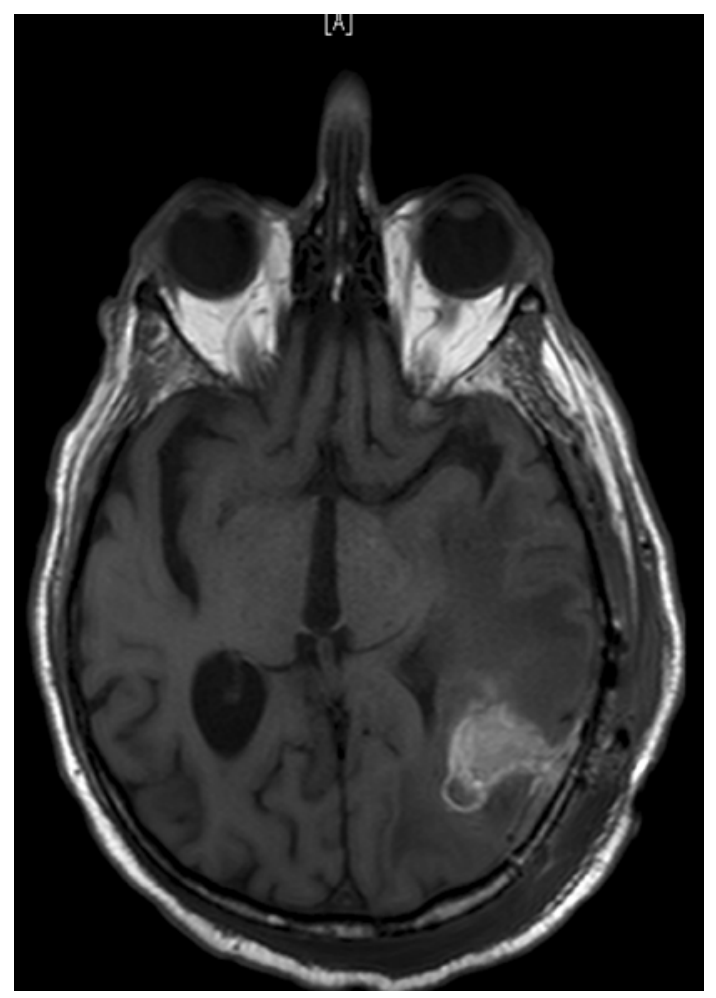

Figure 2. Brain magnetic resonance imaging (MRI) scan showing a cerebral abscess due to Nocardia spp. in a diabetic patient. Diagnosis was confirmed by stereotactic biopsy.

are frequently multiple, but there is no typical presentation (Figure 2). In our series, one patient presented with disseminated disease, and three patients presented brain abscesses without evidence of another infected body site, which are unusual clinical presentations (Table 1). Clinical features of the main nocardial syndromes can be seen in Table 2.

Ocular [34-36], endovascular [37, 38], renal [39], osteoarticular [40], and other localizations have been described in some rare cases in different types of immunosuppressed patients, and even less frequently in patients without immunosuppression. In our series, one previously healthy patient presented a septic arthritis after a traumatic inoculation. Evolution was favorable after surgical debridement and treatment with trimethoprim-sulfamethoxazole. Joints and bones can be reached by direct inoculation or by contiguous spread in immunocompetent patients. On the other hand, they can also be reached by hematogenous spreading from the lungs in immunocompromised patients with disseminated disease.

Although Nocardia infection has been reported as a disease with a high morbidity and mortality rate, the crude mortality rate was less elevated in our series, being $14 \%$.

\section{Diagnosis}

The clinical and radiographic findings in pulmonary, disseminated, and cutaneous nocardiosis are non-specific and may be mistaken for a variety of other bacterial infections, including actinomycosis and tuberculosis, as well as fungal infections and malignancies affecting the lungs, the skin, and the brain [4]. Nocardiosis must be suspected in immunocompromised patients with acute, sub-acute, or chronic pneumonia, or in those with central nervous system or skin and soft tissue involvement. Alertness to the possibility of nocardiosis can expedite the diagnostic work-up, especially in patients with predisposing factors. The diagnosis of Nocardia requires the isolation and identification of the organisms from a clinical specimen. Since nocardial colonies may take up to 2 weeks to appear, it is important to notify the laboratory when Nocardia infection is suspected, so that appropriate measures can be taken to optimize the recognition and recovery of the organism. Nocardia can disseminate to virtually any organ and, thus, clinical samples can vary. As most cases are pulmonary, the most frequent samples are sputum and bronchoalveolar lavage, or other respiratory specimens. Other samples are skin biopsies,

\begin{tabular}{|c|c|c|c|}
\hline Clinical presentation & Primary cutaneous nocardiosis & Pulmonary nocardiosis & Disseminated nocardiosis \\
\hline Susceptible patients & $\begin{array}{l}\text { Agricultural workers, traumatic } \\
\text { exposure }\end{array}$ & $\begin{array}{l}\text { Chronic pulmonary disease, } \\
\text { deficient cell-mediated } \\
\text { immunity }\end{array}$ & Deficient cell-mediated immunity \\
\hline Main clinical features & $\begin{array}{l}\text { Dermo-hypodermitis, } \\
\text { lymphangitis, or mycetoma }^{a}\end{array}$ & $\begin{array}{l}\text { Acute, sub-acute, or chronic } \\
\text { pneumonia, cavitation, } \\
\text { nodular infiltrates, or abscesses, } \\
\text { pleural effusion or empyema }\end{array}$ & $\begin{array}{l}\text { Lung affectation with subcutaneous } \\
\text { or cerebral abscesses }{ }^{\text {b }} \text {; every organ } \\
\text { potentially affected }\end{array}$ \\
\hline $\begin{array}{l}\text { Main clinical differential } \\
\text { diagnosis }\end{array}$ & $\begin{array}{l}\text { Sporotrichosis and other } \\
\text { subcutaneous mycoses, } \\
\text { fungal mycetomas }\end{array}$ & $\begin{array}{l}\text { Bacterial lung abscesses, } \\
\text { tuberculosis, aspergillosis, } \\
\text { and other opportunistic fungal } \\
\text { infections }\end{array}$ & $\begin{array}{l}\text { Bacterial brain abscesses, abscesses } \\
\text { in other organs, aspergillosis, } \\
\text { and other opportunistic fungal } \\
\text { infections }\end{array}$ \\
\hline
\end{tabular}


aspiration from fluid collections, cerebrospinal fluid, and biopsy material [23].

Nocardia is rarely considered as a contaminant in the laboratory, and each isolate must be carefully evaluated [41]. Serology is usually not useful, as no single serological technique can detect all of the clinically relevant species. Moreover, antibody response is usually impaired in immunocompromised patients [3].

Microscopic and macroscopic examination of specimens submitted for culture is the first step in providing a diagnosis [3]. Staining with modified acid-fast stain, and especially gram stain, is particularly important to provide a rapid presumptive diagnosis while awaiting the results of the culture [13]. Most Nocardia are acid-fast in direct smears if a weak acid is used for decoloration. Gram stain and modified acid-fast stain must be considered for the initial evaluation of a possible case of nocardiosis, and samples may have to be repeated if the initial specimens are negative, but there is a high clinical suspicion of infection. Tubercle bacteria can be differentiated given that they are microscopically different, and mycobacteria do not stain well with gram stain and modified acid-fast stain. Similarly, Actinomyces can be differentiated from Nocardia, as they are not stained by modified acid-fast stain [4]. Nocardia spp. can grow on most non-selective media used routinely for the culture of bacteria, fungi, and mycobacteria. In general, the colonies have a chalky white or cotton ball appearance because of the presence of abundant aerial filaments [23]. However, in specimens such as sputum containing mixed flora, Nocardia colonies can be easily covered by other bacteria with a more rapid growing capacity. The yield can be increased by the use of selective media such as Thayer-Martin agar with antibiotics, but the suspicion of Nocardia infection must be transmitted to the laboratory. Although the growth of Nocardia species may take from $48 \mathrm{~h}$ to 3 weeks, typical colonies are usually seen after 3 to 5 days [42].

When the microorganism has been isolated, multiple laboratory tests can be used to differentiate the species. Initial species identification can be performed by biochemical reactions. A set of nine tests allows the identification of $N$. asteroides sensu strictu, $N$. transvalensis $(N$. asteroides IV), $N$. farcinica, $N$. otitidiscaviarum, $N$. brasiliensis, N. pseudobrasiliensis, $N$. transvalensis, $N$. brevicatena, and $N$. nova [41]. However, Nocardia taxonomy is under continuous revision and final speciation may require confirmation in some cases by molecular techniques such as 16S rRNA sequencing, polymerase chain reaction (PCR), and real-time PCR, which may change the initial biochemical identification [43-45]. Agreement of molecular techniques with conventional methods ranges between 70 and $90 \%$ [46]. However, this technology is not available in all clinical microbiology laboratories. Species typification is very important since different species have different resistance profiles, and this information is crucial in order to adjust the antibiotic treatment [3]. The distribution of Nocardia species according to the clinical presentation at our center is shown in Table 1.

Although there is no specific radiologic pattern for pulmonary or disseminated nocardiosis, some radiographic findings have been reported more frequently and can suggest the diagnosis. In pulmonary nocardiosis, nodular images and cavities are frequently seen in the chest radiograph and computed tomography (CT) scan [13, 47]. Cavities are especially common among HIV-infected individuals [20]. Brain images frequently demonstrate abscesses in disseminated nocardiosis [48-50], but they are no different from those produced by other bacteria. Brain abscesses can also mimic other conditions, particularly malignancy and cerebral metastasis [50]. Since neurological symptoms may be very subtle initially in patients with disseminated nocardiosis, a brain CT scan or, preferably, magnetic resonance imaging (MRI) should always be performed to exclude neurological involvement [49].

Although the diagnosis can be confirmed frequently without invasive samples, such as sputum, surgical procedures are required on some occasions to obtain specimens to exclude or confirm the nocardial etiology of the process. This may be particularly important for neurological involvement in immunocompromised patients in whom the spectrum of microorganisms can be broader than in immunocompetent hosts $[28,49,50]$. In this clinical setting, stereotactic brain biopsy should be considered for patients with cerebral abscesses [49, 51-53].

\section{Treatment}

As nocardiosis is a rare disease, the most appropriate therapeutic agent, administration route, and treatment duration have not been well established in clinical trials. Most recommendations are based on the results of basic research, animal models, and clinical expert opinions. Sulfonamides have been the agents of choice for the treatment of nocardiosis for more than 60 years. However, in patients with severe or disseminated disease, the mortality rate remains elevated with sulfonamide monotherapy, and relapses are frequent. Moreover, these drugs are associated with a high incidence of adverse events, such as allergic reactions or severe nausea [54]. Different species have different antimicrobial resistance profiles, and some may be resistant to sulfonamides, as well as particular strains [55]. For these reasons, an initial combination therapy with two or more active agents is recommended for patients with disseminated or severe nocardiosis. According to the clinical presentation, the evolution, and the involved body site, adjuvant surgical treatment may be necessary. Primary prophylaxis is generally not considered because of the overall low incidence of nocardiosis [23].

Although susceptibility tests for all clinically significant Nocardia isolates are recommended, clinicians usually start treatment empirically when these results are still 


\begin{tabular}{|c|c|c|c|}
\hline & Primary cutaneous nocardiosis & Pulmonary nocardiosis & Disseminated nocardiosis \\
\hline \multirow[t]{3}{*}{ Suggested initial treatment } & $\mathrm{TMP} / \mathrm{SMX}$ & TMP/SMX & Imipenem + amikacin \\
\hline & TMP/SMX + fluoroquinolone & TMP/SMX + ceftriaxone & TMP/SMX + imipenem + amikacin \\
\hline & & $\begin{array}{l}\text { TMP/SMX + moxifloxacine } \\
\text { Imipenem + amikacin }\end{array}$ & TMP/SMX + ceftriaxone + amikacin \\
\hline \multirow[t]{3}{*}{ Doses } & $10 \mathrm{mg} / \mathrm{kg} / \mathrm{d}$ of TMP ${ }^{\mathrm{a}}$ & $10-20 \mathrm{mg} / \mathrm{kg} / \mathrm{d}$ of $T M P^{a}$ & $500 \mathrm{mg}$ qid $+15 \mathrm{mg} / \mathrm{kg} / \mathrm{d}$ qd \\
\hline & Ciprofloxacin $500-750 \mathrm{mg}$ bid & $\begin{array}{l}10-20 \mathrm{mg} / \mathrm{kg} / \mathrm{d} \text { of TMP } \\
+2,000 \mathrm{mg} \mathrm{qd}\end{array}$ & $\begin{array}{l}10-20 \mathrm{mg} / \mathrm{kg} / \mathrm{d} \text { of TMP } \\
\text { qid }+15 \mathrm{mg} / \mathrm{kg} / \mathrm{d} \text { qd }\end{array}$ \\
\hline & Moxifloxacine $400 \mathrm{mg}$ qd & $\begin{array}{l}10-20 \mathrm{mg} / \mathrm{kg} / \mathrm{d} \text { of TMP } \\
\quad+400 \mathrm{mg} \text { qd } \\
500 \mathrm{mg} \text { qid }+15 \mathrm{mg} / \mathrm{kg} / \mathrm{d} \mathrm{qd}\end{array}$ & $\begin{array}{l}10-20 \mathrm{mg} / \mathrm{kg} / \mathrm{d} \text { of TMP }{ }^{\mathrm{a}}+2,000 \mathrm{mg} \\
\mathrm{qd}+15 \mathrm{mg} / \mathrm{kg} / \mathrm{d} \mathrm{qd}\end{array}$ \\
\hline Main side effects & $\begin{array}{l}\text { Rash, bone marrow suppression, } \\
\text { urinary lithiasis }\end{array}$ & $\begin{array}{l}\text { Rash, bone marrow suppression, } \\
\text { urinary lithiasis renal toxicity, } \\
\text { hypersensitivity }\end{array}$ & $\begin{array}{l}\text { Rash, bone marrow suppression, } \\
\text { urinary lithiasis renal toxicity, } \\
\text { hypersensitivity }\end{array}$ \\
\hline Comments & $\begin{array}{l}\text { A fluoroquinolone must be } \\
\text { considered for deep } \\
\text { infections, especially } \\
\text { mycetoma }\end{array}$ & $\begin{array}{l}\text { TMP/SMX monotherapy only in } \\
\text { immunocompetent patients } \\
\text { with mild disease. Combination } \\
\text { therapy is preferred in the } \\
\text { immunocompromised }\end{array}$ & $\begin{array}{l}\text { Linezolid could replace any of the } \\
\text { proposed drugs. At least } 2 \text { week } \\
\text { of initial IV treatment is } \\
\text { recommended. Surgical treatment } \\
\text { must be considered for deep } \\
\text { abscesses }\end{array}$ \\
\hline References & {$[3,9,22,56-58]$} & {$[3-5,55,56]$} & {$[3,5,55,56,60-62]$} \\
\hline
\end{tabular}

not available. A suggested initial treatment for the main nocardial syndromes can be seen in Table 3. For patients with serious disease, central nervous system involvement, and/or disseminated infection, some experts recommend a three-drug regimen comprising trimethoprim-sulfamethoxazole, amikacin, and either ceftriaxone or imipenem, which covers all clinical isolates, as no report of resistance to this combination has been indicated $[3,56]$. Other authors consider that there is no need to include sulfonamides in the initial regimen and that imipenem plus amikacin is a good initial combination [5, 55]. In our series, $92 \%$ of tested strains were sensitive to imipenem, and all of the tested strains were sensitive to amikacin, but other aminoglycosides were less reliable. However, the potential problem with the imipenem/amikacin association may be the presence of a strain resistant to the $\beta$-lactam in a patient with central nervous system involvement. In this clinical situation, treatment may be insufficient due to the limited penetration of aminoglycosides into the central nervous system. Although ertapenem may be an attractive alternative to imipenem (once-daily administration and intramuscular availability), it was tested in our center for one strain susceptible to imipenem, which revealed it to be ertapenem-resistant. Thus, susceptibility within the carbapenems group can probably not be extrapolated from imipenem. Trimethoprim-sulfamethoxazole was active in vitro in $84 \%$ of tested strains and intermediate in one. Although trimethoprim-sulfamethoxazole was initially started in 15 patients, six cases had to be switched to another treatment because of side effects or a lack of efficacy. Minocycline was another potentially useful drug, and was tested as susceptible in nine of ten strains tested and intermediate in the other.

Ceftriaxone showed good activity against most of the tested strains, except against $N$. farcinica isolates, which must always be considered as resistant if sensitivity tests are not available.

Treatment must be started and continued for several weeks intravenously and then switched to oral therapy after the initial clinical improvement. It is not clear if trimethoprim-sulfamethoxazole is more active than the sulfonamide component alone but, in some countries, trimethoprim-sulfamethoxazole is the only intravenous sulfonamide available.

Initially, the recommended dose is $10-20 \mathrm{mg}$ of trimethoprim. Later, the daily dose could be decreased to $5-10 \mathrm{mg} / \mathrm{kg}$ of trimethoprim divided into 2-4 doses [54]. For immunocompetent patients with all forms of cutaneous nocardiosis, trimethoprim-sulfamethoxazole monotherapy may be adequate $[11,57]$ or used in combination with moxifloxacin or ciprofloxacin, particularly for mycetoma [58].

When the speciation and sensitivity tests are available, treatment can be adjusted and oral agents can be considered in order to continue therapy. Other potentially useful drugs, according to the species involved, are cephalosporins (ceftriaxone, cefotaxime, and cefepime), other $\beta$-lactams such as amoxicillin-clavulanic acid, minocycline, fluoroquinolones (especially moxifloxacin, which is more 
active than ciprofloxacin), and linezolid. Most of the isolates of $N$. farcinica are resistant to the cephalosporins, but cephalosporins are very active against $N$. asteroides type VI, $N$. nova, and $N$. abscessus. The latter is the species that is more frequently resistant to imipenem. The fluoroquinolones are active to most of the $N$. farcinica and $N$. brasiliensis strains. $N$. brasiliensis is also frequently susceptible to amoxicillin-clavulanic acid [3].

Linezolid has shown very significant in vitro activity against most of the species and strains tested [59]. Although clinical experience is still limited, there are some reports of good clinical response even with central nervous system involvement [60-62]. Thus, linezolid has become an attractive alternative to trimethoprimsulfamethoxazole, imipenem, or amikacin for the empirical initial treatment and can be administered orally for the follow-up treatment.

However, in a recent report, although the number of patients was small $(n=11), 45 \%$ developed myelosuppression and $18 \%$ neuropathy as a side effect of linezolid treatment for nocardiosis [61]. In our institution, linezolid was used for one immunosuppressed patient after trimethoprim-sulfamethoxazole intolerance, but it was stopped for thrombocytopenia. Moreover, the cost of this agent still remains very high.

The duration of therapy is variable and depends on the site of the lesions and the patient immune status. Primary cutaneous nocardiosis can be treated for 13 months. However, mycetoma requires more prolonged therapy. Pulmonary and disseminated nocardiosis without central nervous system involvement should be treated for 6 months at least [23]. For patients with central nervous system involvement, the duration must be established according to clinical and imaging responses, but it usually needs to be continued for a year or longer. In HIV-infected patients with a low CD4 T-cell count and transplanted patients, a secondary prophylaxis with an active oral agent needs to be maintained until the immune status improves [20].

Some nocardiosis sites may require adjunctive surgical treatment, particularly for patients with brain abscesses. However, the optimal treatment approach has not been established and nocardial brain abscesses have been managed either conservatively with stereotactic aspirations or with open craniotomy and enucleation $[49,63$, 64]. Thus, each case needs a careful multidisciplinary evaluation by the primary physician, the infectious diseases specialist, and the surgeon. Mycetoma, some ocular infections, and rare cases with other body sites involvement may require surgical treatment [37, 65-69].

The disease has a tendency to recur and exacerbations can occur even during maintenance therapy if antibiotic concentrations are not optimal. Thus, doses and antibiotic levels must be carefully monitored in immunosuppressed patients, particularly if the clinical evolution is not favorable [16].

\section{Acknowledgments}

We would like to thank Mrs. Rosemary Sudan for editing our manuscript prior to submission.

\section{References}

1. McNeil MM, Brown JM: The medically important aerobic actinomycetes: epidemiology and microbiology. Clin Microbiol Rev 1994; 7: 357-417.

2. Filice GA: Nocardiosis in persons with human immunodeficiency virus infection, transplant recipients, and large, geographically defined populations. J Lab Clin Med 2005; 145: 156-162.

3. Brown-Elliott BA, Brown JM, Conville PS, Wallace RJ Jr: Clinical and laboratory features of the Nocardia spp. based on current molecular taxonomy. Clin Microbiol Rev 2006; 19: 259-282.

4. Yildiz O, Doganay M: Actinomycoses and Nocardia pulmonary infections. Curr Opin Pulm Med 2006; 12: 228-234.

5. Matulionyte R, Rohner P, Uçkay I, Lew D, Garbino J: Secular trends of Nocardia infection over 15 years in a tertiary care hospital. J Clin Pathol 2004; 57: 807-812.

6. Beaman BL, Burnside J, Edwards B, Causey W: Nocardial infections in the United States, 1972-1974. J Infect Dis 1976; 134: 286-289.

7. Yildiz O, Alp E, Tokgoz B, Tucer B, Aygen B, Sumerkan B, Couble $A$, Boiron $\mathrm{P}$, Doganay $M$ : Nocardiosis in a teaching hospital in the Central Anatolia region of Turkey: treatment and outcome. Clin Microbiol Infect 2005; 11: 495-499.

8. Hui CH, Au VW, Rowland K, Slavotinek JP, Gordon DL: Pulmonary nocardiosis re-visited: experience of 35 patients at diagnosis. Respir Med 2003; 97: 709-717.

9. Ferrer A, Llorenç V, Codina G, De Gracia-Roldán J: Nocardiosis and bronchiectasis. An uncommon association? Enferm Infecc Microbiol Clin 2005; 23: 62-66.

10. Satterwhite TK, Wallace RJ Jr: Primary cutaneous nocardiosis. JAMA 1979; 242: 333-336.

11. Inamadar AC, Palit A: Primary cutaneous nocardiosis: a case study and review. Indian J Dermatol Venereol Leprol 2003; 69: 386-391.

12. Fukuda H, Saotome A, Usami N, Urushibata O, Mukai H: Lymphocutaneous type of nocardiosis caused by Nocardia brasiliensis: a case report and review of primary cutaneous nocardiosis caused by $N$. brasiliensis reported in Japan. J Dermatol 2008; 35: 346-353.

13. Martínez R, Reyes $S$, Menéndez R: Pulmonary nocardiosis: risk factors, clinical features, diagnosis and prognosis. Curr Opin Pulm Med 2008; 14: 219-227.

14. Khan BA, Duncan M, Reynolds J, Wilkes DS: Nocardia infection in lung transplant recipients. Clin Transplant 2008; 22: 562-566.

15. Lopez FA, Johnson F, Novosad DM, Beaman BL, Holodniy M: Successful management of disseminated Nocardia transvalensis infection in a heart transplant recipient after development of sulfonamide resistance: case report and review. J Heart Lung Transplant 2003; 22: 492-497.

16. Kakihana K, Ohashi K, Iguchi $M$, Negishi K, Suzuki T, Shitara M, Honma M, Akiyama H, Sakamaki H: Frequent exacerbation of pulmonary nocardiosis during maintenance antibiotic therapies in a hematopoietic stem cell transplant recipient. Int J Hematol 2007; 86: 455-458.

17. Hamadani M, Benson DM Jr, Blum W, Garzon R, Devine SM: Pulmonary Nocardia and Aspergillus co-infection in a patient with chronic graft-versus-host disease. Transpl Infect Dis 2008; 10: $24-26$. 
18. Husain S, McCurry K, Dauber J, Singh N, Kusne S: Nocardia infection in lung transplant recipients. J Heart Lung Transplant 2002; 21: 354-359.

19. Peleg AY, Husain S, Qureshi ZA, Silveira FP, Sarumi M, Shutt KA, Kwak EJ, Paterson DL: Risk factors, clinical characteristics, and outcome of Nocardia infection in organ transplant recipients: a matched case-control study. Clin Infect Dis 2007; 44: 1307-1314.

20. Biscione F, Cecchini D, Ambrosioni J, Bianchi M, Corti M, Benetucci J: Nocardiosis in patients with human immunodeficiency virus infection. Enferm Infecc Microbiol Clin 2005; 23: 419-423.

21. Rasheed MU, Belay G: Nocardiosis in HIV seropositive clinically suspected pulmonary tuberculosis patients. Trop Doct 2008; 38 : 34-35.

22. Uttamchandani RB, Daikos GL, Reyes RR, Fischl MA, Dickinson GM, Yamaguchi E, Kramer MR: Nocardiosis in 30 patients with advanced human immunodeficiency virus infection: clinical features and outcome. Clin Infect Dis 1994; 18: 348-353.

23. Corti ME, Villafañe-Fioti MF: Nocardiosis: a review. Int J Infect Dis 2003; 7: 243-250.

24. Pintado V, Gómez-Mampaso E, Cobo J, Quereda C, Meseguer MA, Fortún J, Navas E, Moreno S: Nocardial infection in patients infected with the human immunodeficiency virus. Clin Microbiol Infect 2003; 9: 716-720.

25. Chouciño C, Goodman SA, Greer JP, Stein RS, Wolff SN, Dummer JS: Nocardial infections in bone marrow transplant recipients. Clin Infec Dis 1996; 23: 1012-1019.

26. Arduino RC, Johnson PC, Miranda AG: Nocardiosis in renal transplant recipients undergoing immunosuppression with cyclosporine. Clin Infect Dis 1993; 16: 505-512.

27. Elenkov IJ: Glucocorticoids and the Th1/Th2 balance. Ann N Y Acad Sci 2004; 1024: 138-146.

28. Ono M, Kobayashi Y, Shibata T, Maruyama D, Kim SW, Watanabe T, Mikami Y, Tobinai K: Nocardia exalbida brain abscess in a patient with follicular lymphoma. Int J Hematol 2008; 88: 95-100.

29. Kundranda MN, Spiro TP, Muslimani A, Gopalakrishna KV, Melaragno MJ, Daw HA: Cerebral nocardiosis in a patient with $\mathrm{NHL}$ treated with rituximab. Am J Hematol 2007; 82: 1033-1034.

30. Ansari SR, Safdar A, Han XY, O'Brien S: Nocardia veterana bloodstream infection in a patient with cancer and a summary of reported cases. Int J Infect Dis 2006; 10: 483-486.

31. Christidou A, Maraki S, Scoulica E, Mantadakis E, Agelaki S, Samonis G: Fatal Nocardia farcinica bacteremia in a patient with lung cancer. Diagn Microbiol Infect Dis 2004; 50: 135-139.

32. Pruitt AA: Nervous system infections in patients with cancer. Neurol Clin 2003; 21: 193-219.

33. Sharma NL, Mahajan VK, Agarwal S, Katoch VM, Das R, Kashyap $M$, Gupta P, Verma GK: Nocardial mycetoma: diverse clinical presentations. Indian J Dermatol Venereol Leprol 2008; 74: $635-640$.

34. Yin X, Liang S, Sun X, Luo S, Wang Z, Li R: Ocular nocardiosis: HSP65 gene sequencing for species identification of Nocardia spp.. Am J Ophthalmol 2007; 144: 570-573.

35. Bharathi MJ, Ramakrishnan R, Vasu S, Meenakshi, Chirayath A, Palaniappan R: Nocardia asteroides keratitis in South India. Indian J Med Microbiol 2003; 21: 31-36.

36. Javadi MA, Kanavi MR, Zarei S, Mirbabaei F, Jamali H, Shoja M, Mahdavi M, Haghshgar N, Yazdani S, Faramarzi A: Outbreak of Nocardia keratitis after photorefractive keratectomy: clinical, microbiological, histopathological, and confocal scan study. J Cataract Refract Surg 2009; 35: 393-398.

37. Gates JD, Warth JA, McGowan K: Nocardia asteroides-infected aneurysm of the aorta: case report and review of the literature. Vascular 2006; 14: 165-168.
38. Kontoyiannis DP, Ruoff K, Hooper DC: Nocardia bacteremia. Report of 4 cases and review of the literature. Medicine (Baltimore) 1998; 77: 255-267.

39. Van Luin A, Manson WL, van der Molen L, van der Heide JJ, van Son WJ: An intrarenal abscess as presenting symptom of an infection with Nocardia farcinica in a patient after renal transplantation. Transpl Infect Dis 2008; 10: 214-217.

40. Baraboutis IG, Argyropoulou A, Papastamopoulos V, Psaroudaki Z, Paniara O, Skoutelis AT: Primary sternal osteomyelitis caused by Nocardia nova: case report and literature review. Braz J Infect Dis 2008; 12: 257-259.

41. Saubolle MA, Sussland D: Nocardiosis: review of clinical and laboratory experience. J Clin Microbiol 2003; 41: 4497-4501.

42. Ashdown LR: An improved screening technique for isolation of Nocardia species from sputum specimens. Pathology 1990; 22: 157-161.

43. Roth A, Andrees S, Kroppenstedt RM, Harmsen D, Mauch H: Phylogeny of the genus Nocardia based on reassessed 16S rRNA gene sequences reveals underspeciation and division of strains classified as Nocardia asteroides into three established species and two unnamed taxons. J Clin Microbiol 2003; 41: 851-856.

44. Tatti KM, Shieh WJ, Phillips S, Augenbraun M, Rao C, Zaki SR: Molecular diagnosis of Nocardia farcinica from a cerebral abscess. Hum Pathol 2006; 37: 1117-1121.

45. Alfaresi $M$, Elkosh A: Rapid identification of clinically relevant Nocardia species using real-time PCR with SYBR Green and melting-curve analysis. J Med Microbiol 2006; 55: 1711-1715.

46. Cloud JL, Conville PS, Croft A, Harmsen D, Witebsky FG, Carroll KC: Evaluation of partial $16 \mathrm{~S}$ ribosomal DNA sequencing for identification of Nocardia species by using the MicroSeq 500 system with an expanded database. J Clin Microbiol 2004; 42: 578-584.

47. Smilack JD: Images in clinical medicine. Pulmonary and disseminated nocardiosis. N Engl J Med 1999; 341: 885.

48. Gezici AR, Daglioglu E, Ergungor F, Okay O, Polat O: Cerebral abscess caused by Nocardia nova. Neurol Neurochir Pol 2008; 42: 153-156.

49. Diego C, Ambrosioni JC, Abel G, Fernando B, Tomás O, Ricardo N, Jorge B: Disseminated nocardiosis caused by Nocardia abscessus in an HIV-infected patient: first reported case. AIDS 2005; 19: 1330-1331.

50. Kennedy KJ, Chung KH, Bowden FJ, Mews PJ, Pik JH, Fuller JW, Chandran KN: A cluster of nocardial brain abscesses. Surg Neurol 2007; 68: 43-49.

51. Chakrabarti P, Nandi SS, Todi SK: Nocardia brain abscess in a diabetic patient. Indian J Pathol Microbiol 2008; 51: 151-153.

52. Vialle R, Aghakhani N, Otayza F, Monteanu V, Safi H, Tadie M: Nocardia farcinica brain abscess: clinical and specific radiological findings and management. Report of two cases in immunononcompromised patients. Neurochirurgie 2002; 48: 516-521.

53. Marnet D, Brasme L, Peruzzi P, Bazin A, Diallo R, Servettaz A, Bernard MH, Rousseaux P, De Champs C, Jaussaud R, Scherpereel B: Nocardia brain abscess: features, therapeutic strategies and outcome. Rev Neurol (Paris) 2009; 165: 52-62.

54. Wallace RJ Jr, Septimus EJ, Williams TW Jr, Conklin RH, Satterwhite TK, Bushby MB, Hollowell DC: Use of trimethoprim-sulfamethoxazole for treatment of infections due to Nocardia. Rev Infect Dis 1982; 4: 315-325.

55. Hitti W, Wolff M: Two cases of multidrug-resistant Nocardia farcinica infection in immunosuppressed patients and implications for empiric therapy. Eur J Clin Microbiol Infect Dis 2005; 24: 142-144.

56. Lerner PI: Nocardiosis. Clin Infect Dis 1996; 22: 891-903. 
57. Maraki S, Scoulica E, Alpantaki K, Dialynas M, Tselentis Y: Lymphocutaneous nocardiosis due to Nocardia brasiliensis. Diagn Microbiol Infect Dis 2003; 47: 341-344.

58. Negroni R, López Daneri G, Arechavala A, Bianchi MH, Robles AM: Clinical and microbiological study of mycetomas at the Muñiz hospital of Buenos Aires between 1989 and 2004. Rev Argent Microbiol 2006; 38: 13-18.

59. Brown-Elliott BA, Ward SC, Crist CJ, Mann LB, Wilson RW, Wallace RJ Jr: In vitro activities of linezolid against multiple Nocardia species. Antimicrob Agents Chemother 2001; 45: 1295-1297.

6o. Moylett EH, Pacheco SE, Brown-Elliott BA, Perry TR, Buescher ES, Birmingham MC, Schentag JJ, Gimbel JF, Apodaca A, Schwartz MA, Rakita RM, Wallace RJ Jr: Clinical experience with linezolid for the treatment of Nocardia infection. Clin Infect Dis 2003; 36: 313-318.

61. Jodlowski TZ, Melnychuk I, Conry J: Linezolid for the treatment of Nocardia spp. infections. Ann Pharmacother 2007; 41: 1694-1699.

62. Ntziora F, Falagas ME: Linezolid for the treatment of patients with central nervous system infection. Ann Pharmacother 2007; 41: 296-308.
63. Valarezo J, Cohen JE, Valarezo L, Spektor S, Shoshan Y, Rosenthal G, Umansky F: Nocardial cerebral abscess: report of three cases and review of the current neurosurgical management. Neurol Res 2003; 25: 27-30.

64. Dahan K, El Kabbaj D, Venditto M, Pastural M, Delahousse M: Intracranial Nocardia recurrence during fluorinated quinolones therapy. Transpl Infect Dis 2006; 8: 161-165.

65. Devi KR, Singh LR, Devi NT, Singh NS: Subcutaneous nocardial abscess in a post-renal transplant patient. Indian J Med Microbiol 2007; 25: 279-281.

66. Lichon V, Khachemoune A: Mycetoma: a review. Am J Clin Dermatol 2006; 7: 315-321.

67. Clare G, Mitchell S: Iris root abscess and necrotizing sclerokeratitis caused by Mycobacterium abscessus and presenting as hemorrhagic anterior uveitis. Cornea 2008; 27: 255-257.

68. Gokhale NS, Garg P, Rodrigues C, Haldipurkar S: Nocardia infection following phacoemulsification. Indian J Ophthalmol 2007; 55: 59-61.

69. Shah HR, Zamboni WA, Khiabani KT: Nocardial septic arthritis of the wrist diagnosed and treated by arthroscopy. Scand J Plast Reconstr Surg Hand Surg 2005; 39: 252-254. 